\title{
11 Food corporation allegiance or worker solidarity? Summoning restaurant worker solidarity in the age of COVID-19
}

\author{
Whitney Shervey
}

The death of Breonna Taylor and George Floyd in 2020 ignited the Black Lives Matter uprising that catalyzed the United States and beyond to face the death and destruction that is structural racism. Through this death and destruction comes life and restoration, unifying people to come together and fight against the systems that create and maintain systemic oppression. This rings true for the people of color who are challenging the inequities they face during the COVID-19 global pandemic. It has been over a year since the first case of COVID-19 was detected in the United States, causing a wave of constant change for everyone. As a global pandemic, COVID-19 is still wreaking havoc across the world and the food system. Food workers are a lynchpin to our survival, yet their essential function is often dismissed or forgotten. The intersection of COVID-19 and structural racism pandemics have unearthed injustices that have plagued restaurant workers for far too long, bringing to the surface the reality that our food system was built and thrives on structural racism.

At the intersection of gender and race, women of color are disproportionately impacted by low wages and face additional inequities brought on by the COVID-19 pandemic. Intersectionality recognizes that identities are complex, therefore how people benefit from or are disadvantaged by the power dynamics of social structures are distinctly variable. Many women of color work in low-paying fast-food jobs; a sector of the food industry that has been fairly resilient to the fluctuation of COVID-19 restrictions due to the convenience nature of the fast-food business model. Likewise, restaurants are searching for resilient measures to abide by COVID-19 protocols that in the end put workers at risk. This resiliency is reflected in corporate profits, not in the health and safety of the workers, leaving women of color who work in the restaurant industry no choice but to risk their lives to feed their own families. The restaurant industry's lack of paid sick leave and 
health insurance forces women of color to work in unsafe environments with little choice to elevate their concerns. Accordingly, women of color are leading worker-led movements to challenge this risk and the many injustices restaurant workers endure. Restaurant corporations are quick to make statements claiming their commitment to addressing racism, yet their lack of cooperation with worker-led movements suggests their investments are elsewhere.

This chapter first examines structural racism in the restaurant industry and COVID-19. It then covers income inequality at the intersection of gender and race followed by the corporate response to the intersecting pandemics. Finally, it explores restaurant-worker-led movements in the face of COVID-19 and the Black Lives Matter uprising, ending with a summoning of solidarity.

Structural racism and COVID-19 within the food system are plaguing workers of color in an industry that is already known for having low standards for taking care of its employees. According to ongoing data on COVID19 cases, hospitalizations, and deaths by race/ethnicity by the Centers for Disease Control and Prevention (2021), Black, African American, and non-Hispanic persons are reporting cases, hospitalizations, and deaths of COVID-19 at rates greater than those of white persons (CDC 2021). Additionally, social determinants of health play a role in comorbidities that put restaurant workers of color at greater risk of dying from COVID-19 once contracted (Nittle 2020). In other words, living in food apartheids, facing chronic food insecurity, and working in low-wage jobs like food service can create health conditions that increase complications or morbidity rates for people that contract COVID-19. Restaurant workers facing food insecurity that subsequently increases their risk of dying from COVID-19 is structural racism and a major flaw and injustice of the food system.

The restaurant industry has been hit hard by COVID-19 and the people impacted the most severely are the workers. Across the United States, restaurants have been forced to close their doors, lay off workers, and pivot their operations to abide by rules and regulations to limit the spread of COVID-19. Workers risk their lives to go to work, forcing them to place their lives in the hands of customers. Along with having their safety and well-being put into the hands of the customer, restaurant workers are in constant fear of unemployment due to the oscillating reopening phases that are determined by the state. Indeed, states deciding to tighten restrictions is a needed measure to mitigate the spread of COVID-19, yet the constant flux of employment-unemployment harms restaurant workers as they often do not know if their most recent paycheck will be their last.

The employment-unemployment flux is not the only threat to restaurant workers; in fact, the risk that restaurant workers are taking to feed America 


\section{Whitney Shervey}

is a deadly one. A recent study evaluating the death records from the California Department of Public Health by sector/occupation and by race/ ethnicity (Chen et al. 2021: 2-8) suggests that food and agriculture workers have the highest mortality rate from COVID-19 with excess mortality occurring in high-risk occupations, with the highest being cook, and also occurring for Black, Latino, and Asian workers across all sectors and occupations (Chen et al. 2021). To put it bluntly, restaurant workers are dying from COVID-19 at rates higher than other occupations and, regardless of occupation, Black, Latino, and Asian workers have a higher excess mortality rate. These higher mortality rates are likely because Black, Latino, and Asian workers make up the majority of the workforce in sectors and occupations deemed essential. It is concerning that food and agriculture workers have the highest mortality rate by occupation compared to healthcare workers, many of whom are taking care of COVID-19 patients. It is easy to understand why workers who are not essential and have the option to work from home are not represented in excess mortality rates from COVID-19. However, it is concerning that health care workers, who are often interacting directly with COVID-19 patients are not at as high a risk of contracting COVID-19 as are restaurant workers. Restaurant workers risking their lives to feed America with little to no option for protecting themselves from the risk of COVID-19 leads me to wonder why restaurant workers are at such high risk and why it is that they are unable to be protected from this risk.

Restaurant workers lack access to paid sick leave and health benefits, forcing them to contend with the paradox of protecting their own health, the health of others, and a paycheck with little to no support from employers or the food industry at large. According to the Food Chain Workers Alliance 2011 survey, of the 630 respondents, 60 percent of food system workers lack access to paid sick time and 58 percent do not have health care coverage (Lo and Oliva 2020: 103). In fact, the inadequate COVID-19 safety protocols and the lack of contact tracing within restaurant establishments puts restaurant workers at greater risk while on the job (Waxman 2020). Additionally, as states roll out their vaccine plans it is up to them to determine who they will prioritize. Some states have prioritized vaccinating restaurant workers in early phases while other states like Oregon have not (Frane 2021). This is troubling considering that many states are open or are reopening for indoor dining, therefore increasing the risk of restaurant workers contracting COVID-19 while on the job. Although I should know better by now, I am still shocked that the people we entrust with feeding the public are forced to choose between a paycheck and their own health. Before COVID-19, this was a public health issue that resulted in outbreaks of norovirus and other foodborne illnesses. In the age of COVID-19, the lack of access to sick leave and health benefits is compounding a public 
health crisis and is costing restaurant workers their lives. Ultimately, trust in leadership is dismal for restaurant workers especially for those workers bound by the low wage for tipped workers of US\$2.13 an hour.

Restaurant workers making US\$2.13 an hour are confronted with additional obstacles during COVID-19. In many states, tipped workers receive a minimum wage of US\$2.13 from their employer assuming that with the tips that they receive they will bring home the state's non-tipped minimum wage. This form of wage structure is often referred to as a two-tier system and is highly problematic. Having a subminimum wage creates opportunities for employers to take advantage of tipped workers and leaves tipped workers vulnerable during times with little to no customer interface. On account of restrictions on indoor dining, many tipped workers have had their hours cut, been shifted to other duties, or been laid off. Additionally, workers that receive US $\$ 2.13$ can find it difficult to receive unemployment because their wages are often seen as too low to qualify. Moreover, in the age of COVID-19, the delivery service landscape of how food is getting to customers is threatening wages for tipped workers by positioning tipped delivery drivers and tipped restaurant workers in a face-off over tips. Depending on the delivery service, who receives the tip varies among delivery service, restaurant, delivery driver, and restaurant worker. The reality is, delivery service corporations are benefiting the most from the increase in deliveries during COVID-19 (Sharma 2021). While some delivery services allow customers to tip the restaurant or delivery workers, others keep the tips for themselves, ultimately hurting restaurant workers at the intersection of gender and race.

Restaurant workers are distressed by low wages that are magnified by income inequality stratification along the lines of gender and race. Entmacher et al. (2014) report that women of color are disproportionately represented in low-wage work like fast-food and according to Reyes et al. (2015) are often segregated into the lowest-paying positions (Entmacher et al. 2014: 1; Reyes et al. 2015: 1). Segregated into the lowest-paid positions means that women often work for tips and in states with a tipped minimum wage of US\$2.13 an hour, women are facing significant economic hardship during the global pandemic. Women work in food service occupations that are the lowest-paying and similar to income inequality across all sectors make less than their male counterparts working in the same occupation. On top of facing the lowest wages, women endure a culture of hypermasculinity and misogyny that normalizes sexual harassment and transphobia in the workplace. Both structural racism and gender inequality are at play here, making me wonder how corporations are responding.

The Black Lives Matter uprising that swept across the country and around the world in 2020 is not only a call to defund the police, but is also a call 


\section{Whitney Shervey}

to address the structural racism that has forever plagued the United States. Following the days after George Floyd's death, fast-food corporations like McDonald's, Burger King, Wendy's, and the Pacific Northwest Burgerville fast-food chain made statements on how they are committed to addressing racism. Workers have challenged these corporations to address intersectional inequalities in their workplace and the corporations have fought back to silence workers and their demands. Knowing their anti-worker history, fast-food corporations announcing their support for the uprising is alarming. If fast-food corporations do not support those who are leading movements within their own companies to address the inequities they are experiencing, how can we trust that their commitments to addressing inequity will be met? Who will hold them accountable? (Figure 11.1)

Fast-food workers know their struggle and have been fighting to challenge fast-food corporations through worker-led movements such as Fight for $\$ 15$ for years. In response to corporations making insincere claims and not responding to the needs of restaurant workers, in July of 2020 fastfood work stoppages across the nation took place in support of the Strike for Black Lives (Saxena 2020). Fast-food workers are the vanguard of this movement as they organize workers across the nation, sign petitions for hazard pay, strike, and lead the charge in increasing the federal minimum wage. Similar to workers across the food system, like the Teamsters at Hunts Point Produce Market Workers' Union striking to the first Instacart

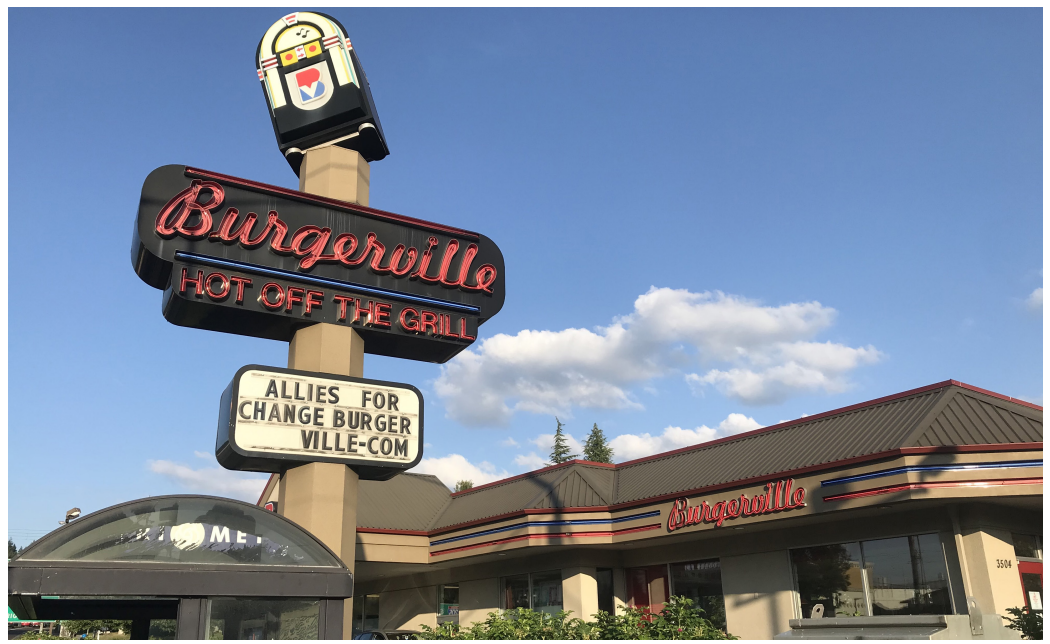

Figure 11.1 Burgerville's Allies for Change sign, July 2020 (Whitney Shervey). 


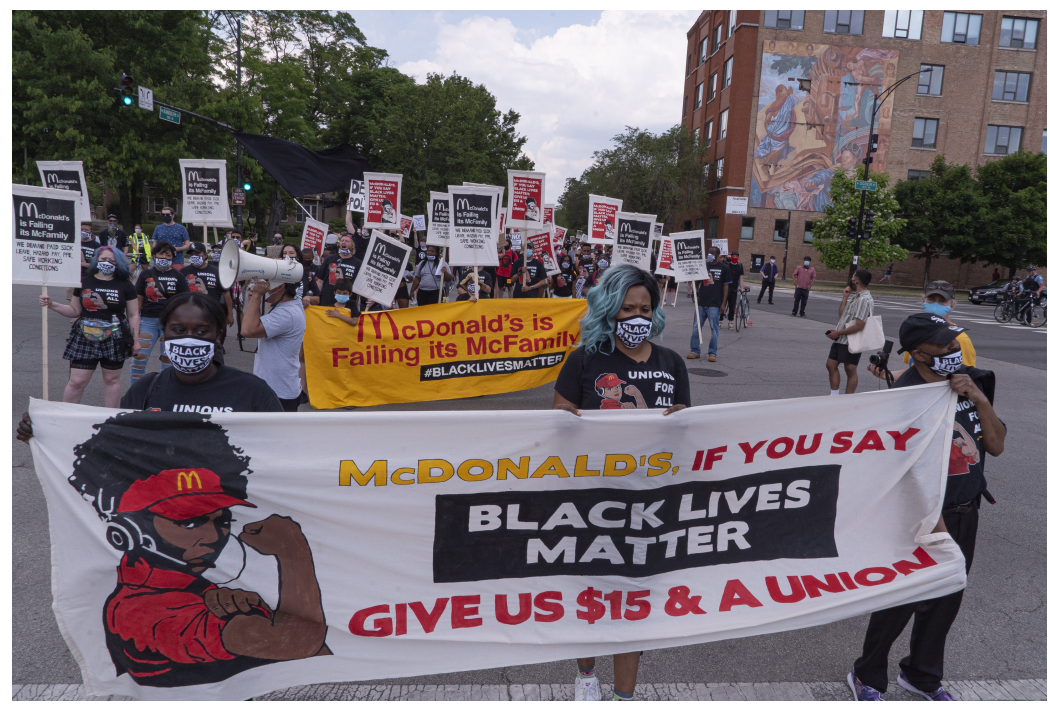

Figure 11.2 Chicago McDonald's workers on strike (Brusky 2020).

union in Illinois, to grocery store workers enduring the ongoing battle with hazard pay, the organizing of restaurant workers is a direct reaction to the conditions workers are experiencing while working during the COVID-19 pandemic (Figure 11.2).

COVID-19 has pushed restaurant workers to their boiling point, creating optimal conditions for unprecedented organizing in the workplace. Since the historical unionizing of the Burgerville Workers Union in Portland, Oregon in 2018, other restaurant workers have been organizing and unionizing. This precedent has given restaurant workers actionable ways to address inequities in the workplace through worker power. During the pandemic, the Burgerville Workers Union is using their power to challenge inadequate responses to address COVID-19 by their employers (Food Chain Workers Alliance 2021: 22). Other workers are organizing for the first time and are confronting their employers' racism. Hailing from the tourist destination Voodoo Doughnuts in Portland, Oregon, Doughnut Workers United began their organizing efforts in 2020 and are asking for Voodoo Doughnuts to not only recognize their union but also change their racist business name. Unionized restaurant workers have the leverage to challenge workplace safety during COVID-19, yet their ability to hold their employers accountable when they are making hollow 


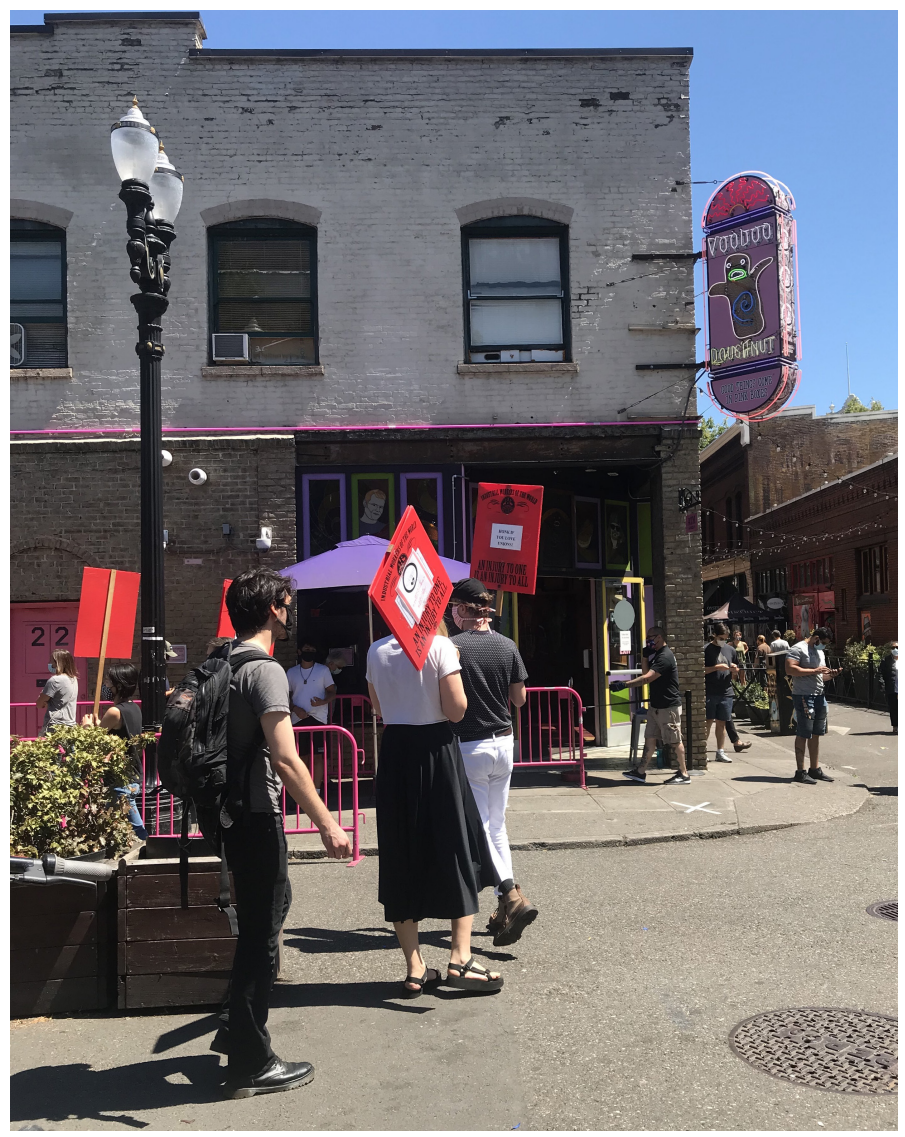

Figure 11.3 Doughnut Workers United on the picket line, July 2020 (Whitney Shervey).

claims to address structural racism needs the support of their customer base (Figure 11.3).

In the age of COVID-19, more than ever convenience has become a priority for eaters and that convenience comes with a cost. From the fast-food drive-through to the delivery services of the gig economy, COVID-19 has strengthened consumer relationships with convenience. This convenience is made possible by structural racism that disproportionately impacts women of color. Whether you are relying on restaurant workers or delivery drivers to keep you fed or are another worker in the food system, I urge you to look beyond the statements coming from the top and find solidarity in worker-led 
movements. Fast-food chains already have a platform and do not need their voices amplified. So, the next time you see them making claims on their social media, think twice before pressing the "Like" button.

My task is to ask all of you to take it upon yourself to know what workers are already doing to address inequality in their workplace. I ask you to trust the experiences of the workers and hold corporations accountable when they are making sweeping claims of how they plan to address racism. I also ask you to reflect on what solidarity means to you. To me, solidarity means showing up knowing that the struggle of the folks you are showing up for is your struggle. It is the role of white people to figure out how your struggle intersects with Black Lives Matter and to show up. It is the role of customers to figure out how your struggle intersects with restaurant workers and show up.

Please, show up!

\section{References}

Brusky, J. (2020) 'Fight for \$15 Show Us Black Lives Matter.' image, Flickr, Available July 24, 2020 at: https://www.flickr.com/photos/40969298@N05 /50025996817/

CDC (Centers for Disease Control and Prevention) (2021) COVID-19 Hospitalization and Death by Race/Ethnicity. Atlanta, GA: National Center for Immunization and Respiratory Diseases Division of Viral Diseases. Available at: https:// www.cdc.gov/coronavirus/2019-ncov/covid-data/investigations-discovery/ hospitalization-death-by-race-ethnicity.html [Accessed: 2.14.21].

Chen, Y.H., Glymour, M., Riley, A., Balmes, J., Duchowny, K., Harrison, R., Matthay, E. and Bibbins-Domingo, K. (2021) Excess Mortality Associated with the COVID-19 Pandemic Among Californians 18-65 Years of Age, by Occupational Sector and Occupation: March through October 2020. medRxiv. Available at: https://www.medrxiv.org/content/10.1101/2021.01.21.21250266v1 .full.pdf [Accessed 2.14.21].

Entmacher, J., Frohlich, L., Robbins, K.G., Martin, E. and Watson, L. (2014) Underpaid and Overloaded: Women in Low-wage Jobs. Washington, DC: National Women's Law Center. Available at: https://nwlc.org/wp-content/ uploads/2015/08/final_nwlc_lowwagereport2014.pdf [Accessed 2.14.21].

Food Chain Workers Alliance (2021) We are Not Disposable, Food Workers Organizing on the Covid Frontlines. Los Angeles, CA: Food Chain Workers Alliance. Available at: https://foodchainworkers.org/wp-content/uploads /2021/02/Food-Workers-Organizing-on-the-COVID-Frontlines-FINAL.pdf [Accessed 2.28.21].

Frane, A. (2021) 'With No Clear Vaccination Plan, Portland Restaurant Workers Are Uneasy About Indoor Dining.' Eater Portland, OR. 2.12.21. Available at: https://pdx.eater.com/2021/2/12/22277096/portland-indoor-dining [Accessed 2.20.21]. 


\section{Whitney Shervey}

Lo, J. and Oliva, J. (2020) 'Food workers versus Food Giants.' In Jayaraman, S. and De Master, K. (eds.) Bite Back: People Taking on Corporate Food and Winning. Berkeley, CA: UC Press. pp. 99-106.

Nittle, N. (2020) 'People of Color are at Greater Risk of COVID-19. Systemic Racism in the Food System Plays a Role.' Civil Eats. 5.5.20. Available at: https:/civileats.com/2020/05/05/people-of-color-are-at-greater-risk-of-covid-19 -systemic-racism-in-the-food-system-plays-a-role/ [Accessed 2.20.21].

Reyes, T., Benner, C. and Jayaraman, S. (2015) Ending Jim Crow in America's Restaurants: Racial and Gender Occupational Segregation in the Restaurant Industry. New York, NY: Restaurant Opportunities Center United. Available at: https://chapters.rocunited.org/wp-content/uploads/2015/10/RaceGender_Report LRR.pdf [Accessed 2.14.21].

Saxena, J. (2020) 'Food workers Across the Country Join the Strike for Black Lives.' Eater. 7.20.20. Available at: https://www.eater.com/2020/7/20/21331616 /food-workers-strike-for-black-lives [Accessed 2.21.21].

Sharma, D. (2021) 'The True Cost of Convenience.' Eater. 1.22.21. Available at: https://www.eater.com/22228352/convenience-of-delivery-apps-destroying -restaurants-uber-eats-doordash-postmates [Accessed 2.21.21].

Waxman, N. (2020) 'Chicago Fast-Food workers Say Companies Aren't Protecting Them From COVID-19.' Eater Chicago. 6.10.20. Available at: https://chicago. eater.com/2020/6/10/21285361/taco-bell-mcdonalds-workers-protest-coronviruscovid-19-restaurant-worker-sues-grubhub-chicago [Accessed 2.20.21]. 